\title{
Fronteras íntimas y geopolítica cotidiana en la zona fronteriza entre Estados Unidos-México'
}

\author{
Juanita Sundberg²
}

\begin{abstract}
RESUMEN
Este artículo centra su atención en las fronteras íntimas de la geopolítica para analizar cómo se diseñan y disputan las fronteras políticas a nivel cotidiano. El análisis se basa en los encuentros íntimos entre ciudadanos estadounidenses y objetos dejados por migrantes no documentados en la zona fronteriza de los Estados Unidos y México. Dichos objetos incluyen documentos de identidad, recuerdos personales y también bienes necesarios para sobrevivir, como botellas de agua, mochilas, medicamentos, zapatos y prendas de ropa. Se sugiere que los encuentros íntimos con estos elementos se tornan sitios significativos en la comprensión de las demarcaciones cotidianas de pertenencia que tienen lugar en las zonas fronterizas de Estados Unidos. A partir de un trabajo de campo en Arizona, el artículo ilustra el modo en que las normas culturales respecto a la relación entre comportamiento corpóreo y objetos participan en la producción y desestabilización de las demarcaciones de los "estadounidenses" o de "aquellos que no pertenecen a Estados Unidos". De esta manera, se demuestra el rol que juegan los objetos en la génesis y transformación del poder geopolítico.
\end{abstract}

Palabras clave: Frontera México-Estados Unidos, cuerpo, objetos, geopolítica.

\begin{abstract}
This paper draws attention to the intimate frontiers of geopolitics to analyze how quotidian political boundaries are delineated and disputed through mundane discursive practices. My empirical focus is the USA-Mexico borderlands wherein US citizens frequently encounter material evidence of undocumented immigrants and their (unauthorized) border crossings. The materials encountered include identity documents and personal mementos as well as objects needed for survival like water bottles, backpacks, medication, shoes, and clothes. Close encounters with these intimate objects, I argue, have become primary sites wherein everyday framings of belonging are constituted in the borderlands. Drawing on field research in Arizona, I illustrate how cultural prescriptions for bodily comportment in relation to these objects are enlisted in the production and disruption of quotidian framings of 'American' or 'those who don't belong in America. In this way, I demonstrate the role of objets in the generation and transformation of geopolitical power.
\end{abstract}

Key words: American-Mexican frontier, body, intimacy, objects, geopolitics.

Este artículo constituye la traducción de una versión modificada del texto publicado en el año 2008 en Social \& Cultural Geography, 2008, Vol. 9, № 8 con el título "Trash-talk' and the production of quotidian geopolitical boundaries in the USA-Mexico borderlands". Agradezco a Perla Zusman por su traducción. El primer borrador de este trabajo fue realizado durante mi estancia en el Center for Research in Women's Studies and Gender Relations en la Universidad de British Columbia. Agradezco el apoyo de Geraldine Pratt, su cuidadosa lectura y sus importantes sugerencias. Las críticas de Bonnie Kaserman adquirieron una importancia crucial en el momento en que estaba finalizando mi análisis. Artículo recibido el 30 de marzo de 2016, aceptado el 30 de septiembre de 2016 y corregido el 30 de enero de 2017. 
Tratada convencionalmente como el dominio de actores masculinos de elite, la geopolítica como campo de estudio ha irrumpido a partir de la incorporación de otros actores, cuerpos, objetos, afectos y performances (Dittmer \& Gray, 2010; Fall, 2006; Hyndman, 2004; Kuus, 2007; Raento, 2006; Sharp, 1996, 2001; Squire, 2014, 2015). Las geógrafas feministas juegan un papel crucial, al ampliar y dar cuerpo a los actores, a los objetos y a los sitios para su consideración dentro de la geopolítica (Dowler \& Sharp, 2001; Hyndman, 2001; Staeheli et al., 2004). Contribuyo a este proyecto feminista a través de colocar mi atención en las "fronteras intímas" de la geopolítica (Stoler, 2001: 830).

Lo íntimo como un sitio interior de configuración de la pertenencia ha sido abordado de una forma bastante completa por el trabajo de Ann Laura Stoler (1995, 2002, 2006). Ella ha demostrado que las fronteras culturales y políticas entre colonizador y colonizado fueron delineadas a través de valoraciones cotidianas de las actitudes morales, la competencia cultural y del comportamiento del cuerpo. Las recientes intervenciones de la geografia feminista extendieron lo íntimo más allá de lo doméstico (Pratt \& Rosen, 2006a). Lo íntimo como categoría analítica o como sitio corporifica las relaciones sociales, y los objetos, las actitudes y las prácticas disciplinarias que sirven como fuentes de identificación o de formación identitaria. Visto a través de las lentes de lo íntimo, las fronteras entre lo doméstico y lo nacional se difuman; ellas se pliegan en la textura de la vida cotidiana, tejidas en las historias diarias (Mountz \& Hyndman, 2006: 448).

A fines de explorar "la forma que se ha abordado la geopolítica de la intimidad" (Pratt \& Rosen, 2006b: 19), mi atención se centra en la frontera entre Estados Unidos y México, y específicamente, en los encuentros cercanos entre los ciudadanos estadounidenses, la evidencia material de los migrantes indocumentados y sus movimientos fronterizos (no autorizados). Los materiales encontrados abarcan tanto documentos de identidad, recuerdos personales así como otros elementos necesarios para sobrevivir como botellas de agua, paquetes de comida, medicación, zapatos, ropas y mochilas (De León, 2012). Estos bienes íntimos y banales han recibido gran atención en las frontera: ellos son objeto de una continua cobertura por parte de los medios de comunicación nacionales y locales. En estos medios, dichos elementos son etiquetados de forma contundente como "basura"; ; los objetos figuran en las movilizaciones de un amplio rango de grupos sociales. También ellos adquieren protagonismo en el trabajo de numerosos artistas.

En este artículo considero los encuentros cercanos entre los cuerpos y los objetos como sitios productivos de formas de imaginar la geopolítica cotidiana que genera (e irrumpe) en la demarcación diaria de la pertenencia. Uso el término cotidiano para señalar que la emergencia de narrativas y prácticas a través de estos objetos no emerge de las elites, sino que surge de las aproximaciones cotidianas entre los objetos abandonados en el cruce y los ciudadanos estadounidenses (colectivos e individuales). El término también señala los encuentros entre cuerpos y objetos que se moldean a partir de "las escenas de instrucción íntima" (Pratt y Rosen 2006b: 20). De esta manera se establece como el cuerpo se vincula con los objetos banales de la vida diaria. Considero estas instrucciones como fuentes de identificación y de formación identitaria que son, a la vez, cotidianas y geopolíticas. 
Comienzo este trabajo señalando el contexto político en el que los movimientos fronterizos no autorizados obligan a los inmigrantes indocumentados a llevar estos elementos íntimos y banales. Estos, muchas veces, son perdidos o desechados.

A fin de desarrollar la idea que los encuentros con estos objetos son productivos, en la medida que contribuyen a imaginar la geopolítica cotidiana, esbozo un marco teórico que tiene como propósito examinar las fronteras íntimas de la geopolítica. Posteriormente, me concentro en analizar cómo los objetos y materiales abandonados en el cruce aparecen en el discurso y en las prácticas espaciales diarias en la zona de frontera. En primer lugar identifico las narrativas y prácticas de dos grupos distintos de la frontera en el area de Arizona: por un lado, los clubs políticos que expresan su indignación frente la inmigración no autorizada proveniente del sur, y por el otro, los grupos humanitarios que se aproximan de forma compasiva a los migrantes. Luego, muestro como los artistas trabajan aquellos objetos de modos de generar imaginarios geopolíticos disruptivos.

El estudio se basa en análisis de textos e investigación etnográfica. Mientras llevaba adelante un estudio para un proyecto más amplio sobre las dimensiones ambientales de la seguridad fronteriza, me intrigó el interés ampliamente difundido, y hasta obsesivo, por los objetos que los indocumentados abandonaban en la zona de frontera ${ }^{4}$. A los fines de avanzar en la indagación, comencé a organizar un archivo de producciones discursivas y visuales que abarcaron el periodo comprendido entre 2001 y 2007. El archivo incluye desde artículos académicos, documentos de gobierno, declaraciones del congreso estadounidense hasta artículos de los medios de comunicación y sitios web ${ }^{5}$. A los fines de completar la información de archivo desarrollé una investigación de carácter cualitativo que comprendió visitas a los empleados de la patrulla fronteriza en Texas y Arizona, la participación en "levantamientos de residuos" organizados fundamentalmente por grupos humanitarios de Arizona, y entrevistas a individuos que colaboraron en el levantamiento de estos objetos.

\section{Cambiando las geografías del movimiento fronterizo}

Para los inmigrantes indocumentados, el cruce del límite entre México y Estados Unidos es hoy un viaje que amenaza la propia vida y requiere resistencia física. Mientras que antes los migrantes indocumentados entraban a Estados Unidos a través de las ciudades populosas de la frontera, hoy tienen que recorrer largas distancias a través de terrenos hostiles, escasamente habitados (Cornelius 2001). Este cambio geográfico en el movimiento fronterizo data de 1994, cuando el Servicio de Inmigración y Naturalización de Estados Unidos (INS) inició la estrategia de reforzar la frontera del sureste. Con el objetivo de "prevenir a través de la disuasión", la estrategia buscó hacer que el cruce fuera "tan difícil y costoso para entrar ilegalmente [a los Estados Unidos] que pocos individuos lo intentarían" (INS 1996: 3). Con este propósito, los nuevos operativos de la patrulla fronteriza como la Operación Guardián buscaron desvíar a los migrantes que desearon 
entrar a los Estados Unidos sin autorización hacia áreas "más remotas y difíciles de atravesar" (INS, 1996: 3; Nevins, 2002) (ver Figura Nº 1)

Figura $\mathrm{N}^{\circ} 1$

Las operaciones de la patrulla fronteriza y las nuevas geografías de la migración.

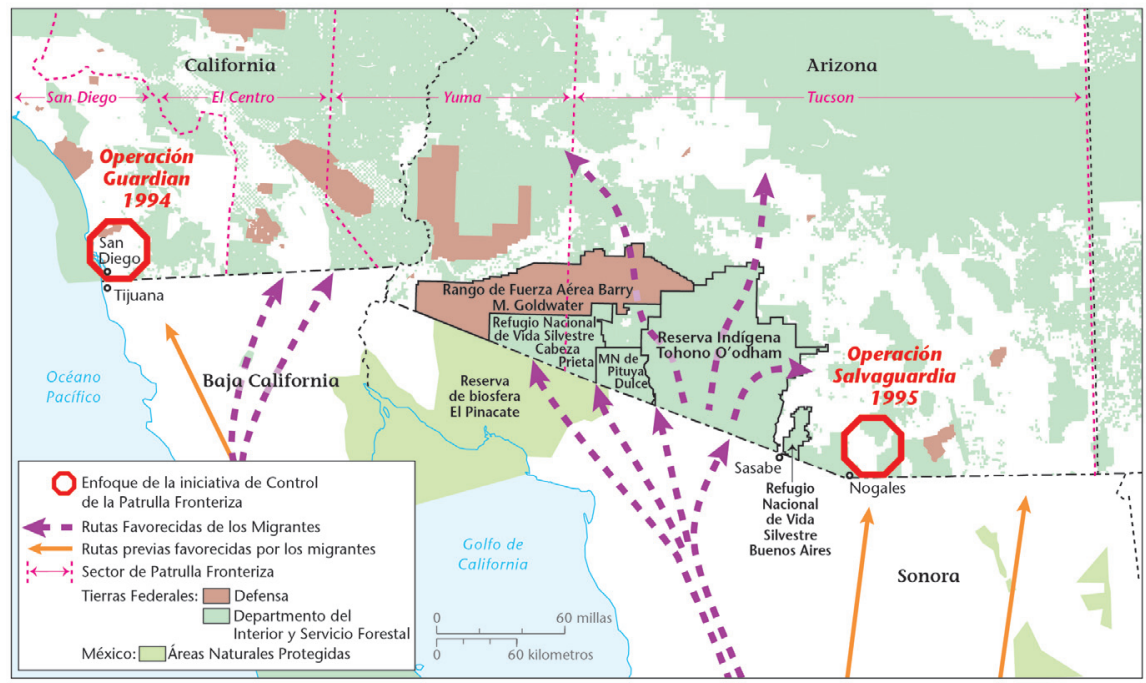

Fuente: Elaborado por Eric Leinberger.

Sin embargo, estas políticas de reforzamiento de la frontera no se acompañaron de mecanismos legales que otorgaran permisos de trabajo a miles de individuos que deseaban trabajar en aquellos sectores de la economía de los Estados Unidos que encuentra la base en su mano de obra (como la agricultura, el empaque de comida, la construcción, entre otros) (Andreas, 2000; Cornelius, 2005). En este contexto político contradictorio, cientos de miles de individuos provenientes de México, América Latina y otros países, sin la documentación requerida intentan cruzar la frontera de todos modos (Van Hook et al., 2005). Como consecuencia de estas condiciones ambientales extremas en estas áreas remotas, los riesgos mortales de atravesar la frontera se han incrementado de forma aguda (Cornelius, 2001).

Resulta imposible calcular el número de muertos, debido a las condiciones ambientales extremas, pero hay algunas estimaciones. Un estudio del gobierno sugiere que el número de decesos se duplicó entre 1995 y 2005 (GAO 2006). La Comisión Nacional de Derechos Humanos de México señaló que más de 3.500 mejicanos murieron desde la puesta en práctica de esta estrategia entre 1994 y 2005 (Frontera NorteSur, 2005). A partir de 1998 la patrulla fronteriza estadounidense empezó a documentar el número de fallecimientos. Así, desde ese año al 2016, se han registrado 6. 915 muertes (CBP, 2016). Para entrar a Estados Unidos bajo el actual regimen de reforzamiento de la frontera, los inmigrantes indocumentados deben llevar comida y agua, así como otros elementos necesarios para sobrevivir. En la medida que los objetos se pierden o son desechados, los inmigrantes indocumentados crean paisajes geográficos específicos, asociados al movimiento fronterizo. Por ejemplo, el cruce a Texas requiere, primero, atravesar el Río Bravo. Para cruzar el río, los individuos flotan en llantas o nadan llevando sus ropas y otros elementos en bolsos de 
plastico. Una vez que hayan efectuado el cruce, ellos desecharán las ropas mojadas que vestían y se pondrán prendas secas; abandonarán el bolso junto con otros elementos que quizás aparten de forma accidental. En Arizona, Californa y Nuevo México los inmigrantes indocumentados deben caminar grandes distancias, atravesando cañones, desiertos o tierras de haciendas. Botellas vacías de agua y contenedores de comida, junto a mochilas desechadas y otros objetos íntimos, constituyen paisajes culturales comunes en estos estados en la actualidad.

Como se mencionó anteriormente, las noticias de los medios de comunicación dedican gran atención a la acumulación de los objetos y materiales abandonados. Semana tras semana, los medios de comunicación nacionales y de los estados publican noticias referidas a los artículos que los inmigrantes abandonan. La edición del domingo del Arizona Daily Star ilustra el tono predominante en estas notas con este titular "Quienes cruzan la frontera sepultan el límite con los desperdicios" (Davis, 2006). Un artículo anterior aparecido en el Arizona Daily Sun incluye una lista de objetos abandonados "Latas de sardinas vacías yacen en el suelo junto a fotos de familiares y contenedores de desodorantes. Ropas desechadas, botellas de agua vacías, y pañales sucios pueblan los costados de los senderos que innumerables inmigrantes ilegales han trazado en la arena" (Rothstein, 2004). A pesar de que los elementos enumerados son necesarios para sobrevivir, ellos son explicitamente etiquetados como residuos. Otro ejemplo, es el Tucson Citizen que enumera el tipo de elementos abandonados y luego cita a un residente del sur de Arizona afirmando que "Nosotros estamos acostumbrados a la presencia de estos desperdicios a lo largo del camino... y a todo eso, es como si hubieran traído todo México aqui... No entiendo como alguien puede tener tanta basura" (Turf, 2003). En este fragmento, la persona que habla hace una asociación explícita entre los inmigrantes indocumentados, los mexicanos y la basura.

Mi análisis basado en 200 registros audiovisuales sugiere que solo unos pocos ofrecen información general o una lectura equilibrada que expliquen el contexto geopolítico y politico más amplio en el que han tenido lugar estos cambios geográficos en el tráfico fronterizo. Tampoco ellas hacen alguna mención a cómo y porqué estos objetos son abandonados. Como consecuencia, "la basura" se torna en objeto de atención de los artículos más que la frontera, las políticas de inmigración. Los inmigrantes documentados son presentados como aquellos que "ensucian" Estados Unidos. Los medios de comunicación no están solos en esta tarea; las autoridades del gobierno han prestado atención a los objetos abandonados. "Toneladas de basura y altas concentraciones de desperdicios humanos son abandonados por los extranjeros indocumentados" sostiene el informe del Congreso referido al impacto de quienes cruzan la frontera en el sureste de Arizona (US DOI, 2002: 3). Aún más, las autoridades electas usan "los residuos" para mobilizar a los constituyentes contrarios a la inmigración. En este sentido, el Congresista Tancredo, que lideró el grupo de la reforma inmigratoria, ha sido un importante portavoz. En una declaración en el Congreso, sostuvo que "Los [immigrantes] se mueven a través de la frontera todo los días y todas las noches. Ellos vierten toneladas de basura y las heces humanas en lugares protegidas por su belleza escénica" (US Congressional Record, 2003: H2918). Tales declaraciones confunden los elementos íntimos necesarios para sobrevivir con excremento. De esta manera, se tilda de manera explícita a los inmigrantes indocumentados como poco higiénicos.

En síntesis, las estrategias de reforzamiento de la frontera han creado un ambiente en el que los inmigrantes indocumentados son obligados a abandonar sus objetos. En este contexto, actores provenientes de una amplia gama de contextos sociales han caratulado a los inmigrantes undocumentados como "aquellos que ensucian Estados Unidos", una perspectiva que se ha di- 
fundido ampliamente en los medios de comunicación. Este artículo sostiene que la práctica de rotular a los objetos abandonados como basura genera formas de imaginar la geopolítica cotidiana y de crear una identidad en términos de "nosotros" y "ellos". El desarrollo de este argumento requiere un giro en la forma en que el geopoder es imaginado y analizado desde la geopolítica. Aún más, requiere de un cambio en el abordaje y una orientacion hacia las fronteras íntimas de la geopolítica. En lo que sigue, esbozaré un marco que se adecua al análisis de tales prácticas geopolíticas cotidianas.

\section{Las fronteras íntimas de la geopolítica}

Frente al hecho de que los objetos que los inmigrantes indocumentados abandonan son banales y necesarios para la sobrevivencia humana, resulta curioso que ellos hayan despertado tanto la atención. ¿Por qué las personas en las zonas fronterizas en los Estados Unidos están tan preocupadas con estos objetos? Para Tim Cresswell (1996: 22), las acciones perturbadoras son metodológicamente útiles, ya que llevan a las personas a definir "que es y que no es apropiado", por lo tanto ellas revelan "los presupuestos que se consideran dados y que ayudan a moldear la acción social". En lo que sigue, me baso en la metodología de Cresswell para centrarme en la intimidad de la geopolítica.

En su clásico estudio sobre pureza y contaminación, Mary Douglas (1984: 2) sostiene que "no existe algo así como lo absolutamente sucio: ello depende del cristal con que se lo mire". La definición de "lo que está sucio" depende de un orden social o de la demarcación de fronteras entre las localizaciones apropiadas o inapropiadas para sustancias y materiales (Sibley, 1995). "Las cosas que transgreden se tornan sucias-ellas están en el lugar equivocado" (Cresswell, 1996: 38). La transgresión y las reacciones que ella provoca destacan los valores considerados apropiados. El proceso de calificación de algo como sucio es una forma a través de la cual se repara o reinstala el orden (Cresswell, 1996).

¿Pero cómo es que las cosas llegan a ser vistas en el lugar correcto o en el lugar errado? Claramente, ellas son posicionadas por sujetos que quedan sometidos a instrucciones íntimas y estas instrucciones tienen que ver en cómo el cuerpo se relaciona con los objetos de la vida cotidiana. Ampliando la fundamentación de Douglas, entonces, el concepto de suciedad depende de la demarcación de las localizaciones apropiadas o no apropiadas, pero también de las prescripciones del comportamiento corporal en relación a los objetos íntimos y a los materiales de la vida cotidiana. Desde esta perspectiva, la práctica de rotular los objetos abandonados por los inmigrantes indocumentados como "basura" evoca un conjunto de normas sociales dadas que delinean los modos apropiados o inapropiados de comportamiento. Si el proceso de tildar como "suciedad" o "desperdicios" es una evidencia de las prácticas cotidianas que buscan establecer fronteras como lo sugieren Douglas, Sibley y Cresswell, ¿cómo deberían ser interpretadas estas prácticas a través de las lentes de la geopolítica? ¿Y, qué herramientas se encuentran disponibles para realizar estas interpretaciones?

Por décadas, las fronteras políticas fueron entendidas como líneas fijas, defendidas por las instituciones estatales. Hoy en dia, dichas fronteras son más probablemente definidas como un efecto de procesos sociales y prácticas discursivas que producen distinciones entre grupos geopolíticos (Paasi, 1996, 1999; Berg \& Van Houtum, 2003; Newman, 1999). Este cambio ha derivado en 
el crecimiento de la atención hacia los objetos y prácticas banales, los "pequeños detalles [que] crean el sentido de un "nosotros" que no es igual al de "ellos" (Thrift, 2000: 381, 384). Mientras tanto, las prácticas discursivas diarias han sido un componente de las aproximaciones feministas a los proyectos geopolíticos (al menos) desde la publicación del trabajo de Cynthia Enloe (1983, 1989). Algunos estudios recientes ponen su atención en cómo los objetos-en virtud de su capacidad para actuar o de afectar la acción- participan en la génesis de la transformación del poder (Meehan et al., 2013: 3).

Del mismo modo, las feministas han también sostenido que el cuerpo-concebido como el sitio de prácticas más banales e íntimas-es un emplazamiento importante de la imaginación y de la práctica geopolítica (Enloe, 1989; Hyndman, 2001, 2004; Wastl-Walter \& Staeheli, 2004). Como práctica analítica, la corporificación visibiliza cosas que, de otro modo, quedarían escondidas de la prácticas materiales, cotidianas del geopoder y que permite ofrecer nuevos puntos de vista acerca de la manera en que "los cuerpos de las personas se tornan sitios públicos de violencia en los cuales las construcciones de la nación y de las fronteras tienen lugar" (Hyndman, 2003: 12; Mayer, 2004; Mountz, 2004). Sin embargo, la violencia no es la única modalidad a través de la cual el cuerpo se convierte en un sitio de la imaginación política. Como se señaló antes, los estudios de Ann Stoler $(1995,2002,2006)$ destacan cómo las instrucciones en las prácticas íntimas en la vida diaria trabajan para moldear las fronteras sociales y políticas entre "nosotros" y "ellos". Para Stoler (2002), la categorización de tipos específicos de sujetos y cuerpos es fundamental para construir el cuerpo político y, por extensión, para establecer las estrategias de inclusión y exclusión. Stoler llama la atención respecto al trabajo "cultural y político" sostenido que continua elaborando estas distinciones. Como ejemplo, Stoler (2006) y otros especialistas poscoloniales señalan las prácticas prescriptivas asociadas al deseo carnal, las prácticas que definen arreglos espaciales vinculadas a la vida doméstica; las prácticas en relación a la crianza de los hijos, las instrucciones ligadas a la higiene doméstica, etc, como ámbitos importantes para asegurar las identificaciones (Clancy-Smith \& Gouda, 1998; Magubane, 2004; McClintock, 1995). Estas instrucciones íntimas del comportamiento corporal participan en la definición de las coordenadas culturales y políticas de pertenencia (Stoler, 2006).

El marco teórico elaborado aqui establece un diálogo entre la literatura referida a la geografía de la exclusion, la geopolítica feminista y los estudios poscoloniales, a fin de sostener que las prescripciones íntimas del comportamiento corporal en relación con los objetos de la vida cotidiana son aprovechadas a los fines de construir y naturalizar categorías unificadas de las personas en la zona de fronteras entre Estados Unidos y México. Sobre la base de las transgresiones percibidas, los inmigrantes indocumentados son producidos como una categoría de personas que se comportan de forma inapropiada al abandonar sus pertenencias íntimas en el lugar incorrecto. De esta manera, ellos son calificados como "aquellos que ensucian Estados Unidos". El proceso de catalogación actúa de manera tal de producir simultaneamente otro grupo, el de los "estadounidenses", que conocen cómo y dónde disponer los objetos de manera apropiada. Finalmente, las concepciones cotidianas de la pertenencia nacional y de las fronteras geopolíticas se generan a través de referencias a un conjunto de normas íntimas, que a su vez, son naturalizadas como parte del sentido común. Por lo tanto, ellas van más allá de la ideología y de la política en el sentido formal.

Mi posición solamente se fortalece si consideramos que la higiene ha sido por mucho tiempo una fuente importante de construccion de la zona de frontera entre México y Estados Unidos, 
como ha sucedido con otras localizaciones sociales (Kraut, 1994; Sibley, 1995). Por ejemplo, cuando Texas fue parte de México, los colonizadores ingleses tejieron ideas acerca de la higiene racial en el marco de supuestos sobre el aseo corporal a los fines de estigmatizar los residentes mexicanos como sucios (De León 1983). Estas construcciones continuaron cuando Texas fue incorporada en los Estados Unidos a los fines de caracterizar a los mexicanos y a los mexicano-estadounidenses como poco limpios y, por lo tanto, sin condiciones de tornarse ciudadanos. La noción del "mejicano sucio" se arraiga profundamente en la cultura estadounidense, especialmente en los estados que antes formaban parte de México. En los inicios del siglo veinte, por ejemplo, los ciudadanos mexicanos que deseaban entrar en Estados Unidos vía Texas eran sometidos a prácticas eugenésicas: en Laredo, ellos eran bañados, examinados físicamente y luego, en sus brazos se estampaba la palabra "admitido"; en El Paso, hasta 1938 ellos eran rociados con químicos y sus ropas fumigadas (Stern, 2005; Romo, 2005) ${ }^{6}$. En el caso de los trabajadores agrícolas, estas prácticas continuaron hasta la década de 1950.

Steven Bender (2003) sostiene que tales asociaciones y las prácticas relacionadas, han contribuido a la marginalización de los Latinos en el sistema legal y a justificar su segregación geográfica (Menchaca, 2001; Ngai, 2004). En síntesis, "la conversación sobre la basura" resuena en las zonas fronterizas debido a la larga historia de asociación cultural que vincula los cuerpos de los mexicanos y de los latinos estadounidenses con contaminación (Hill, 2006).

En la próxima sección, se analiza cómo es que los objetos abandonados configuran las movilizaciones políticas de los actores sociales en las zonas de frontera. Mi interés se concentra en los encuentros cercanos con estos objetos: ¿qué es lo que las personas hacen con ellos? ¿Y qué es lo que estas (re) organizaciones en el paisaje dicen acerca de los ciudadanos y de los inmigrantes indocumentados? ¿Cómo es que "nosotros" y "ellos" son imaginados? Finalmente, deseo identificar el papel cultural y político que los objetos juegan en la génesis y transformación de las distinciones geopolíticas cotidianas.

\section{Construyendo la frontera en los bordes}

En septiembre de 2003, un grupo de ciudadanos estadounidenses en el Condado de Cochise, Arizona, dejó veintidós bolsas con "botellas de plástico de agua, ropas, zapatos, productos de higiene femenina y latas de comidas usadas" en la oficina del congresista estadounidense Jim Kolbe (representante por Arizona), quien había propuesto una legislación para trabajadores visitantes, a los fines de proveer con visados temporarios a los trabajadores migrantes (Hess, 2003). El Sierra Vista Herald informó que las bolsas contenían objetos dejados por los migrantes indocumentados cuando viajaban a pie a través del condado (Hess, 2003). Una de las bolsas fue inscrita con mensajes que explicaban el propósito de esta acción política. "iNosotros aún estamos siendo invadidos! Aqui hay algunas pruebas," decía un mensaje. Y, un pedazo de cartón contenía la siguiente proclamación: "Señor Kolbe, es su deber defender la Constitución. Cierre nuestras fronteras. Proteja los ciudadanos estadounidenses y su ambiente". De acuerdo al artículo de Sierra Vista Herald, los manifestantes aparentemente acusaron a Kolbe de "no hacer nada para evitar la degradación del ambiente por los inmigrantes ilegales" (Hess, 2003).

Los científicos alemanes elogiaron el método de fumigación de El Paso y adoptaron los procedimientos tanto en los movimientos transfronterizos en Alemania como en los campos de concentración en la década de 1940 (Romo, 2005). 
En sus intervenciones políticas, los ciudadanos estadounidenses usan los objetos dejados por los migrantes indocumentados para expresar su visión sobre las políticas migratorias y sobre los migrantes. A pesar de que ellos constituyeran parte integral de la vida diaria y de que fueran necesarios para la sobrevivencia de los migrantes, los manifestantes producían estos objetos como desechos, colocándolos en bolsas de basura. Este movimiento señala la percepción de una transgresión: los objetos fueron dejados en lugares equivocados. Además, las bolsas fueron usadas como fundamento para delinear las fronteras entre "ciudadanos" e "invasores", como lo indicaban los mensajes adjuntos. El término "invadido" sugiere una transgresión de las fronteras nacionales y las bolsas de basura se empleaban como "prueba" de que la invasión habíatenido lugar. Más aún, los "invasores" eran considerados responsables de "degradar" el ambiente, señalando que ellos habían transgresido el conjunto de normas sociales dadas que definían modos de comportamiento corporal apropiados e inapropiados. Aquí, la intimidad y la geopolítica se pliegan de forma conjunta, en la medida que los ciudadanos estadounidenses usan los objetos abandonados para producirse así mismos como "estadounidenses" y a los migrantes indocumentados como "invasores" o como "aquellos que no pertenecen a Estados Unidos".

Luego de que las bolsas de basura fueron arrojadas en la oficina de Kolbe, un sitio de internet titulado "Claiming Responsibility for Trashing Rep. Kolbe's Office with Border Intruder Garbage" (Tomando la responsabilidad por degradar la oficina del Congresista Kolbe con residuos de intrusos de la frontera) exhortaba a los ciudadanos a reconocer su responsabilidad por participar en el activismo de basura. Los manifestantes explicaron de la siguiente manera el raciocinio que los llevó a dejar lo que ellos llamaban "los desechos de extranjeros ilegales" frente a la oficina de Kolbe: Kolbe propuso un programa de trabajador temporario que "dará lugar a una mayor cantidad de extranjeros ilegales $y$, de esta manera, una mayor cantidad de basura de extranjeros ilegales en nuestros desiertos y patios traseros" (Claiming Responsibility, 2003). El sitio de internet también describía el lugar de procedencia de estos objetos: "los residuos fueron reunidos aquel día de un lay-up site [un lugar donde los migrantes descansan o esperan ser recogidos] utilizado por extranjeros ilegales". Además, el sitio de internet afirmaba "que los residuos eran antiestéticos, malolientes y no permitían el acceso del congresista Kolbe a su oficina hasta que ellos fueran retirados" por "ingenieros sanitarios" Ilamados para "desinfectar" la acera, la puerta y las paredes (Claiming Responsibility, 2003).

Podría afirmarse que el programa de trabajador temporario que removía las barreras legales existentes para permitir el ingreso legal de aquellos que desearan trabajar temporalmente en Estados Unidos, derivaría en que menor cantidad de migrantes trabajadores hicieran el viaje a pie, y que, por lo tanto abandonaran menos botellas de agua. Sin embargo, para estos manifestantes, los migrantes parecen implicar necesariamente basura, sin importarles por qué ellos ingresan a Estados Unidos o de dónde ellos provienen (del desierto o del patio trasero). La mención al despliegue de ingenieros sanitarios para limpiar "los residuos" "antiestéticos" y "malolientes" refuerza la asociación entre los trabajadores migrantes y los desechos, y los produce como personas no higiénicas, indisciplinadas, con comportamientos corporales inadecuados.

El activismo en torno a la basura continuó en enero de 2004, cuando Kolbe celebró un encuentro en el Ayuntamiento en Sierra Vista, Arizona. El Southeast Arizona Republican Club ofreció la siguiente descripción de la situación: 
"Los manifestantes trajeron gran cantidad de bolsas de basura que recogieron de un campamento en un arroyo situado cerca del hogar de dos manifestantes. La basura fue colocada a ambos lados de la entrada que llevaba al ayuntamiento donde se celebró el encuentro. Entre los elementos que la basura incluía se encontraban ropas, mochilas, comida deteriorada, latas y envoltorios que llevaban etiquetas mejicanas, objetos de aseo, medicación y curiosamente un conjunto de pasamontañas negros".

El informe afirmaba más adelante: "Kolbe llegó al edificio a través de un camino alternativo a fin de evitar reconocer los desechos".

Aquí, nuevamente, los encuentros cercanos con los objetos abandonados generan prácticas con connotaciones geopolíticas. En este caso, los manifestantes decidieron situar los objetos encontrados en bolsas de basura y los colocaron frente al edificio del ayuntamiento a fin de que todos los vieran. De esta manera, los manifestantes recreanlas transgresiones sociales y políticas que ellos perciben: del mismo modo que los residuos se encuentran fuera de lugar frente al ayuntamiento, los migrantes muestran un comportamiento inapropiado, fuera de lugar, en Estados Unidos. Simultáneamente estas acciones funcionan para producir a los manifestantes como ciudadanos con derechos para expresarse y asociarse libremente. En síntesis, las nociones del sentido común acerca de los comportamientos apropiados se expresan en acciones políticas que usan los objetos abandonados en un intento de definir distinciones geopoliticas entre los "estadounidenses" y "aquellos que no pertenecen a Estados Unidos".

Mientras que la indignación nativista respecto a la inmigración indocumentada es propia de la respuesta que ofrece un gran número de clubes políticos y grupos de ciudadanos, sus visiones no son hegemónicas. Grupos humanitarios preocupados por asegurar a los migrantes indocumentados los derechos a la vida y a la integridad personal abundan en las zonas de fronteras. A su vez, los objetos abandonados aparecen en los discursos y prácticas de estos grupos ${ }^{7}$. El próximo apartado se centra en examinar cómo ellos aparecen en los discursos y prácticas de una de estas organizaciones, Humane Borders (Fronteras Compasivas).

\section{Compasión humanitaria y la geo/política del "levantamiento de la basura"8}

Como se mencionó en el inicio, los cambios en el reforzamiento de la frontera han derivado en el aumento en el número de muertes de migrantes; la mayoria de las muertes ocurren en el Desierto de Sonora; entre 1990-2005, la Oficina del Médico Forense de Tucson, Arizona se ocupó de 927 cuerpos recuperados (Rubio-Goldsmith et al., 2006). En 1999, algunos individuos en Tucson se reunieron a fin de buscar maneras de prevenir estas muertes; muchos habían sido involucrados en el movimiento del Santuario de la década de 1980. Este proveía protección y sostén a gran parte de los refugiados de América Central que buscaban apoyo en Estados Unidos (Cunningham, 1995). En el año 2000, se creó Fronteras Compasivas con el fin de ofrecer "asistencia humanitaria a aquellos que la necesitaran a través de 70 estaciones de agua de emergencia, tanto en la

\footnotetext{
Para una visión diferente de las prácticas humanitarias consultar Squire (2014)

8 Trash Pickups en el original (Nota de la traductora).
} 
frontera como cerca de ella" (HB, página web). Las estaciones de agua son parte del esfuerzo de salvar vidas a través de proveer agua a los migrantes indocumentados que cruzan el desierto. La controversía acosa a Fronteras Compasivas y la organización es acusada de facilitar el ingreso de los migrantes "ilegales" a Estados Unidos mediante las estaciones de agua (Vanderpool, 2003).

\section{"Manteniendo el desierto limpio"}

Curiosamente, el levantamiento de los objetos dejados por los migrantes indocumentados ha sido una de las actividades a la que Fronteras Compasivasha destinado sus esfuerzos desde 2001. Constituye la segunda tarea en importancia a la que se dedican los voluntarios, luego del mantenimiento de las estaciones de agua. Como se señala en el sitio web:

"El segundo sábado de cada mes se precisan voluntarios para levantar los desechos dejados por los migrantes en su camino a través del sur de Arizona" (HB Migrant Encounter Protocols).

El boletín de Fronteras Compasivas vincula esta actividad con el mantenimiento de la limpieza; la protección ambiental también influye en estas narrativas. Por ejemplo, el boletín de noticias de junio de 2003, detalla un levantamiento con la participación del cónsul mexicano y personal del consulado mexicano que trabajaron "para mantener limpio el ambiente frágil del desierto". Una nota correspondiente a noviembre/diciembre de 2003 señala: "A los fines de continuar el buen manejo de las areas ecológicas frágiles de los desiertos del sur de Arizona, los voluntarios son invitados a participar en las jornadas de levantamiento de la basura, el segundo sábado de cada mes". Un boletín correspondiente a febrero/marzo de 2005 presenta fotos de voluntarios e incluye la frase "Manteniendo el desierto limpio". Los boletines mensuales indican el número de bolsos que se llenan. Por ejemplo, un día de marzo 2005, el boletín informa que cuarenta y siete voluntarios colectaron " 45 bolsas de basura y más de 300 botellas de agua vacías en el Monumento Nacional del Bosque Ironwood". A fin de analizar las implicancias de estos discursos, es importante situarlos en el contexto de la geografía del trabajo de Fronteras Compasivas. Fronteras Compasivas mantiene las estaciones de agua en tierras públicas ${ }^{9}$. Uno de los fundadores de Fronteras Compasivas sugiere que los levantamientos de residuos en las tierras públicas son importantes, porque permiten a la organización mantener buenas relaciones con los administradores de las tierras públicas, y juegan un papel clave en el otorgamiento de permisos de uso a la organización. A su vez, permiten conservar las controvertidas estaciones de agua. Un miembro del personal de Fronteras Compasivas se expandió sobre la base de este razonamiento organizacional. Como ella afirma, Fronteras Compasivas es "usuaria" de tierras públicas. Para ella, el derecho a disponer de la tierra pública se acompaña de responsabilidades:

"Salimos de nuestro camino para conseguir [voluntarios], ser buenos custodios del desierto y ciertamente, levantar basura logra este objetivo-mantenerlo, sabes, no solo para que se vea lindo sino tambien para evitar problemas con la vida silvestre".

En Arizona, más del $85 \%$ de la tierra situada en la frontera y del $62 \%$ del área comprendida dentro de las 100 millas de la zona fronteriza es propiedad federal o entregada en fideicomiso a las naciones indigenas estadounidenses (Defenders, 2006: 12). Esta estimación de tierras públicas en Arizona no incluye la tierra del estado, del condado o de la ciudad. 
Desde su punto de vista, estos esfuerzos "otorga un poco de mayor legitimidad a nuestra organización".

"Nosotros cuidamos de forma diligente de nuestras estaciones de agua y levantamos basura. Ello solo se añade a lo que somos, a nuestra identidad, a lo que somos y al hecho que queremos ser buenos ciudadanos".

A través del levantamiento de los desperdicios, el grupo demuestra que ellos son buenos custodios de la tierra y, por lo tanto, buenos ciudadanos. Como buenos ciudadanos, Fronteras Compasivas se presenta a sí misma mereciendo lo buscado: los permisos que les permiten mantener los tanques de agua en tierras públicas.

Uno de los fundadores de Fronteras Compasivas destaca una segunda razón para "sacar la basura del desierto"10. "El público odiaba los residuos", explicaba. "Presentamos una imagen de limpieza y piedad (jaja) para el público". En otras palabras, la limpieza del desierto fomenta una imagen positiva frente al público, que podría contribur a contrarrestar no solo las acusaciones de "ayuda y complicidad" respecto a los migrantes indocumentados, sino tambien a apagar las llamas del sentimiento antiinmigrante fomentado por la evidencia de la presencia migrante en las tierras públicas. A partir del levantamiento de los desperdicios, Fronteras Compasivas muestra respeto por las normas sociales percibidas que equiparan la nacionalidad estadounidense a la idea de pulcritud. En contraste, el abandono de los objetos en el desierto indicaría una desconsideración por las normas, y acarrearía el riesgo de incitar posteriormente la indignación de los grupos anti-inmigrantes. Al equiparar limpieza con piedad, las narrativas del fundador apelan a un orden social construido, en parte, a partir de las prescripciones del comportamiento corporal: la ciudadanía y la pertenencia se asocian con la idea de pulcritud.

¿Qué papel juega "el levantamiento de los residuos" en la práctica? Para ilustrarlo, proporciono un ejemplo de mi investigación como participante/observadora. En julio del 2005 participé en un levantamiento de basura con Fronteras Compasivas en el Monumento Nacional del Bosque Ironwood. Para afrontar el calor del verano, los voluntarios se encontraron en Tucson a las 6:30 de la mañana; luego fuimos llevados a un lugar determinado para unirnos a un grupo de una iglesia de Phoenix. El grupo de unos treinta hombres y mujeres incluía un mejicano-estadounidense; el resto de los miembros eran anglo-estadounidenses. Todos fuimos llevados hacia el oeste hasta que alcanzamos un arroyo situado a 112 kilómetros al norte del límite político con México.

Debido al hecho de que nos perdimos en el camino, eran las 9:00 de la mañana y ya hacía mucho calor cuando salimos de los vehículos con aire acondicionado. Fronteras Compasivas nos proveyó de guantes e implementos para levantar los objetos sin tener que tocarlos (sugiriendo de esta manera que los objetos estaban sucios). Ellos también nos dieron unas bolsas grandes, de color amarillo-verde brillantes, entregadas por la Bureau of Land Management (Departamento Federal de Manejo de la Tierra), que permitía a Fronteras Compasivas disponer los mismos en el vertedero sin costo (ver Figura $\mathrm{N}^{\circ} 2$ ). Los organizadores nos recomendaron mantenernos en grupos de modo de no perdernos, un recordatorio de lo rápido que un cuerpo puede sucumbir en el

Esta entrevista fue realizada vía correo electrónico, el día 29 de octubre de 2005. Se ha autorizado su reproducción. 
desierto. Nosotros seguimos el recorrido del arroyo y empezamos a situar los objetos en bolsas y recoger botellas vacías de agua.

Mientras estábamos caminando a lo largo del arroyo, nos encontramos con un grupo de quince migrantes indocumentados que provenían de México, descansando en la sombra. Ellos nos relataron que habían estado caminando por cinco días y pudimos observar que ellos estaban sufriendo de deshidratación. Les ofrecimos "paquetes para migrantes", bolsas llenas de bocadillos y agua preparadas y donadas por grupos de la iglesia. Un miembro del grupo de Fronteras Compasivas también trató el pie ampollado de un hombre joven. Sin embargo, no podíamos ofrecer asistencia a una mujer que nos dijo que estaba con un embarazo de seis meses, porque el grupo quería continuar con el viaje hacia el norte y Fronteras Compasivas no puede ofrecer transporte para los migrantes indocumentados, al menos que surja una emergencia médica. En ese caso, se contacta a la patrulla fronteriza. Nos alejamos del grupo sabiendo que nunca conoceríamos su destino.

Figura $\mathrm{N}^{\circ} 2$

Elementos entregados para la recolección de objetos

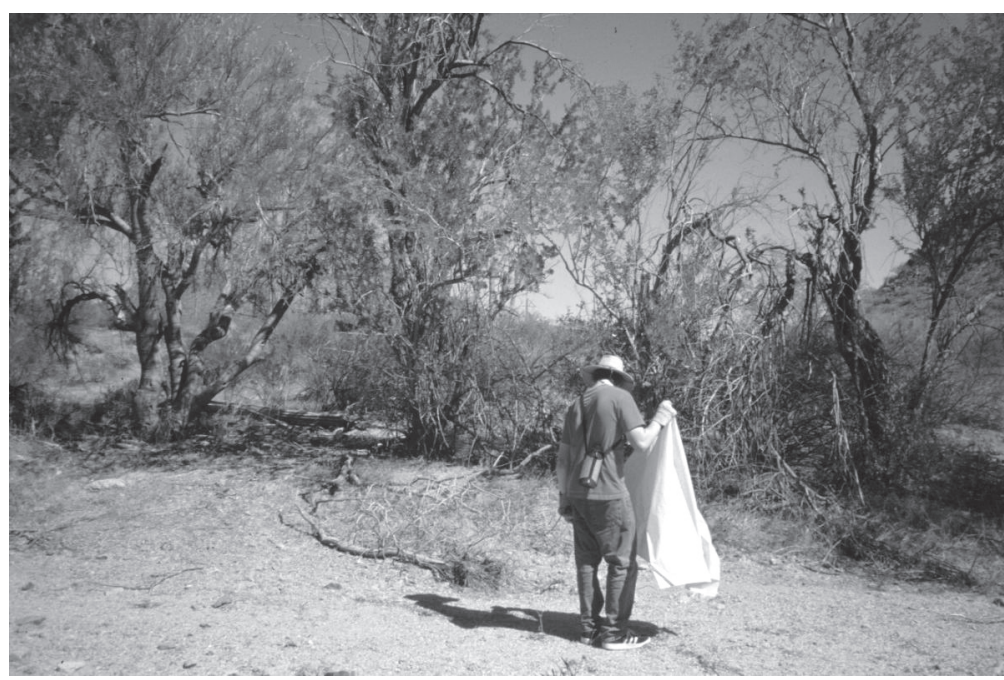

Fuente: Archivo fotográfico personal de la autora.

Inclui estas observaciones a los fines de destacar que los levantamientos de residuos no constituyen excursiones placenteras. En los meses de verano, con temperaturas de 37 a 46 grados, y aún con nuestro acceso privilegiado al agua, alimento y sombra, es fácil deshidratarse o desvanecerse. El levantamiento de los residuos tampoco constituye una actividad particularmente excitante. De hecho, mi experiencia fue bastante agotadora. ¿Por qué entonces, los voluntarios de Fronteras Compasivas están tan "decididos," como dijo uno de los miembros, a "limpiar el desorden"?

Más que enfocarme en las motivaciones individuales, trato "el levantamiento de basura" como un "imperativo organizacional" que personifica una práctica espacial cotidiana que naturaliza la pulcritud como un significante, y que considera la norma social como dada. "La remoción de la suciedad... es parte del establecimiento de un ambiente ordenado" (Cresswell, 1996: 38). 
A través de esta práctica espacial corporificada-narrativizada a través de los discursos de la pulcritud y del deber cívico - Fronteras Compasivas apela y (re)produce un orden social construido, en parte, a partir de claras demarcaciones entre comportamientos corporalmente apropiados e inapropiados en relación a los materiales y sustancias rotuladas como basura. Los "levantamientos de residuos" configuran las tierras públicas, y por extension, la nación como un lugar limpio con ciudadanos que se portan bien, aseados que son merecedores de derechos y responsabilidades. Frente al hecho que ellos limpian lo que otros dejan, estas prácticas espaciales necesariamente emplazan fronteras entre los que limpian y los que abandonan las cosas. ¿Cómo es que esta práctica posiciona a los migrantes, aquellos que han abandonado los objetos?

\section{¿Basura o remanentes?}

Esta es una pregunta que se realiza el personal de Fronteras Compasivas. Por ejemplo, en una entrevista con un miembro del personal, le pregunté acerca de las implicancias de usar el término "basura de migrantes". Ella afirmó que lucha con el término y luego reorientó la entrevista a una exposición patrocinada por Fronteras Compasivas: "Lost and Found: Remnants of a Desert Passage" (Perdidos y encontrados: Remanentes del pasaje por el Desierto) diseñada por la artista irlandesa Maeve Hickey. Hickey recogió objetos abandonados en el desierto y los organizó de una forma que obliga al espectador a "verlos" como lo que son: objetos íntimos integrados a la vida diaria. Como se notifica en el boletín de marzo de 2002 de Fronteras Compasivas, "...la exhibición incorpora objetos dejados por los migrantes en su viaje a través del desierto de esta región". De forma poderosa y poética, las obras de Hickey evocan las experiencias esperanzadoras, frágiles y a veces trágicas de las miles de personas que cruzan la frontera buscando una nueva vida en este país.

Fronteras Compasivas mantuvo en exhibición una de las instalaciones en su sede en la First Christian Church. Dentro de la instalación se incluyeron objetos tales como un cochecito de bebé al que le faltaba una rueda, un zapato de bebé, una muñeca, aguja e hilo, tarjetas de presentación, un pasaje de avión y una bicicleta. La instalación organiza los objetos a los fines de invitar a los espectadores a conjurar imágenes de individuos con familias, deseos y sueños. Elementos como los zapatos de bebés o los juguetes hablan de la domesticidad, de las familias, de la construcción de futuros. El cochecito de bebé, la bicicleta y los billetes de avión -todos signos conmovedores de la movilidad-hablan de la determinación de los migrantes indocumentados de seguir adelante, de avanzar.

La instalación cumple un papel educacional que también se desarrolla en los levantamientos de los residuos. Los empleados de Fronteras Compasivas señalan que los encuentros cercanos con los objetos íntimos, a través de los levantamientos, frecuentemente impulsan a los voluntarios a conectarse con los migrantes indocumentado como individuos. Como lo afirmó un miembro del personal, los objetos provocan "curiosidad y asombro, llevan a una búsqueda de significación". Y, aquellos que se involucran en los levantamientos pueden quedarse pensando qué es lo que pasó con las personas que abandonaron los objetos, ¿Estas personas están aún con vida? ¿Atravesaron el desierto? ¿Dónde están? ¿Su familia lo sabe? Todas estas preguntas surgen, a partir del levantamiento de los residuos.

En el fondo, las prácticas de Fronteras Compasivas provocan imágenes contradictorias. Por un lado, el levantamiento de los residuos se basa en narrativas que vinculan la ciudadanía con deberes civiles como el de levantar "los desperdicios de los migrantes", confirmando de esta manera 
la percepción de que los estadounidenses no solo son los limpios, sino que también son quienes limpian. Sin embargo, el término "basura de los migrantes" se usa para rotular esos objetos, los migrantes indocumentados son construidos como aquellos que no se conportan de manera apropiada y abandonan sus cosas; luego, ellas precisan ser levantadas. Sugiero que estas prácticas emplazan fronteras geopolíticas entre "nosotros" y "ellos", "los estadounidenses" y "aquellos que ensucian Estados Unidos" y, por esa razón, su pertenencia es puesta en cuestión.

Por el otro lado, los encuentros cercanos con los objetos abandonados poseen la potencialidad de construir conexiones emocionales entre los ciudadanos y los migrantes indocumentados. El personal de Fronteras Compasivas y sus voluntarios sugieren que estas conexiones frecuentemente inspiran a los individuos a aprender más acerca de las políticas migratorias estadounidenses, las políticas que crean las circunstancias que obligan a quienes cruzan la frontera sin inspección a caminar a través del desierto. A su vez, estas conexiones podrían impulsar a los ciudadanos estadounidenses a hacerse cargo de transformar las políticas migratorias. ¿Ahora bien, estas transformaciones individuales pueden llevar a quebrar las identificaciones geopolíticas cotidianas constituidas en y a través de la matriz del comportamiento corporal? Quizás esta pregunta sea imposible de responder. En la próxima sección, introduzco a un artista de Tucson cuyas instalaciones ofrecen otros puntos de vista.

\section{Conectándose a través de las fronteras mediante las "pertenencias personales"}

En el año 2005, me presentaron a Pancho, un artista chicano con residencia en Tucson. "Cuando le comenté que estaba interesada en su trabajo acerca de la basura, él me respondió: "Bueno, yo no la llamo basura, la denomino 'pertenencias personales'". Su respuesta me alarmó, resaltando el poder de las representaciones hegemónicas en la comprensión de los objetos dejados como residuos. Como demuestro, Pancho sitúa los objetos de manera que invitan a los espectadores a tomar consciencia y librarse de tales representaciones. A la vez, creo que contribuye a emanciparse de los imaginarios geopolíticos que ellos convocan.

Pancho comenzó a trabajar con objetos abandonados en la migración luego de un viaje a Sasabe, un pueblo de la frontera en Sonora, México, donde miles de personas se preparan para hacer su viaje hacia el norte a través del desierto de Sonora. El viaje a Sasabe inspiró a Pancho a hacer un altar para el Día de los Muertos en el 2001, en honor a aquellos cuyas tentativas de cruce acabaron en muerte. El Día de los Muertos es una importante ceremonia mejicana y mexicana estadounidense que se celebra entre el 1 y 2 de noviembre para homenajear a los ancestros.

Un altar puede contener fotografías de los muertos, flores, velas, ofrendas de comida, cigarillos, licores y otros objetos de importancia para los fallecidos. Pancho hizo un altar que incluía objetos recolectados en distintos sitios del desierto,

"Pensé, el altar puede tener diferentes impactos en la gente, si ellos ven los bienes personales dejados allí por seres humanos reales como usted o yo. Y funciona. Realmente

Agradezco a Dereka Rushbrook que me haya presentado a Pancho. 
funciona porque, de repente las personas, escuchan hablar sobre esto [los viajes por el desierto], hablan sobre esto, pero, cuando van a algun lugar y ven, ven las pertenencias de las personas en exhibición...posiblemente ellos pueden relacionarse un poco con ellas [las pertenencias], formarse un mejor cuadro de lo que está pasando allá afuera".

Según Pancho, su instalación del Día de los Muertos fue un suceso; el afirmó "quiero decir, las personas iban a darle un vistazo, nunca habían visto estas cosas; un altar con este tipo de cosas"12. A través de erigir un altar que incluye ropas y otras cosas que las personas han dejado, Pancho refuta las representaciones predominantes que presentan a estos objetos como basura, y en su lugar, invita a los espectadores a concebirlos como objetos de pertenencia personal, elementos de importancia para quienes fallecieron.

Pancho afirmó que él comprendía la preocupación por la presencia de "basura en el paisaje", un término que usó solo a modo de crítica. "Pienso que es muy fácil culpar a los inmigrantes, en lugar de acusar al gobierno quien fue el que puso a estas personas en esta situación. Nosotros somos seres humanos, póngame en esta situación, yo haré lo mismo". En lugar de inculpar a las personas por arrojar botellas de agua, Pancho sugiere examinar la situación en que se encuentran las propias personas: “¿Por qué estan en esta situación? ¿Quiero decir, quiénes los ponen en esta situación? Su respuesta es "Las políticas desvían a las personas hacia el desierto". El trabajo de Pancho intenta poner la atención en este contexto.

\section{Corporificando las pertenencias personales}

La instalación de Pancho más emotiva quizás sea el omnibus "Altar-Sasabe", realizada con objetos abandonados (ver Figura $\mathrm{N}^{\circ} 3$ ). Altar es en la actualidad el más importante punto de parada interior en Sonora, México para los migrantes indocumentados que se preparan para viajar a Estados Unidos. Pancho se inspiró en la tradición cultural desarrollada por personas que toman minibuses hasta la frontera con el fin de atravesarla. Como el propio Pancho señala "cada vez que entran en el autobús saben que la muerte está con ellos". Al interior del bus "Altar-Sasabe" se encuentran seis manequies que representan los migrantes en los inicios del viaje. A su vez, al interior se sitúa "La Calavera", la figura de un esqueleto que representa la muerta en la cultura popular mexicana. "Lo que ella hace es ofrecer un perfil de cada uno de ellos y explicar por qué ellos se dirigen al norte", explica Pancho. El público es invitado a presionar un botón en una grabadora a los fines de escuchar las historias de La Calavera acerca de cada persona que viaja en el ómnibus, incluyendo la que ella misma acarrea. Así es como ella comienza.

“Déjenme presentarles a estas gentes. A mi derecha se encuentra Juanita. Ella es de Chiapas. Se dirige a Chicago a encontrarse con su marido que trabaja en un restaurant. Ellos tienen que ir al norte porque estaban desempleados en México y no tienen otros medios de subsistencia. Ella pagó a un coyote para que la lleve a Chicago. Ella tuvo que pedir prestado dinero a sus familiares y vender su casita. Pobrecita Juanita".

Esta pieza fue también destacada en el New Internationalist, la revista de activismo radical de mayor circulación en Estados Unidos (ver Ransom, 2002). 
Arriba del ómnibus, Pancho situó las mochilas y las botellas de agua que recogió en los sitios del desierto. Posicionando estos objetos de esta manera, Pancho los presentó como elementos de pertenencia personal que cualquiera podría precisar durante el viaje. En palabras de Pancho:

"A los fines de ir de un lugar a otro, ellos necesitan mochilas, zapatos, ropas, ellos necesitan todo, todas los elementos para sobrevivir. Y gastan mucho dinero en estas cosas...y no querían dejarlos, pero tuvieron que hacerlo, para su propia sobrevivencia, no tuvieron otra alternativa".

En el techo del ómnibus se encuentra una mochila de Barbie todavía con agua en su pequeño termo rosa.

"Supongo que ella [la mochila] perteneció quizás a una niña pequeña. Ella no quería dejarla, ella le costó a su mamá...le costó su dinero. Estas personas provienen de pueblos donde no pueden permitirse una mierda, ellos no quieren dejarlo ahí. No sé por qué las dejan ahi. Hay muchas razones, podemos solo especular. Quizás el coyote estaba allí, esperando y dijo 'ok, deje todas las cosas', y seguro la niña pequeña decía 'no, no, yo quiero llevarla'. 'No, no puedes'. 'Yo quiero llevarla, yo quiero llevarla,' y la madre decía, 'podemos llevarla, sabés, pero ella nos costó mucho dinero'. 'No'".

El relato de Pancho que da vida a la mochila introduce un elemento invisible en las historias sobre los residuos: frecuentemente los coyotes forzan a los migrantes a dejar sus pertenencias en el momento en que son recogidos por el traficante, porque ellos seguramente los señalarán como indocumentados. La patrulla fronteriza tambien juega un papel. Como afirma Pancho, "La Migra es responsable por mucho de esta basura, solo arroja las pertenencias hacia el suelo". Hasta hace poco, una práctica común de la patrulla fronteriza era la de forzar a los migrantes indocumentados a abandonar sus pertenencias en el sitio en que eran detenidos y los obligaban a arrojar sus botellas de agua. Por norma, los agentes supuestamente no pueden más ordenar a las personas a abandonar sus cosas (GNEB, 2007).

El ómnibus "Altar-Sasabe" invita a los espectadores a conectarse con los migrantes indocumentados. Al concebir a los objetos como elementos que todos necesitamos y usamos en la vida diaria, la instalación representa a los migrantes indocumentados como viajeros que precisan de ellos para resistir el viaje. Al exponer la mochila de Barbie arriba del bus, Pancho también sugiere que los migrantes compran muchos objetos de consumo de la misma marca de aquellos que compran "los estadounidenses" ¿Qué diferencias podría haber si nosotros compramos y usamos el mismo tipo de cosas?

Aún más, el ómnibus "Altar Sasabe" opera con el fin de corporizar y humanizar a los migrantes a través de contar historias que explican por qué ellos viajan hacia el norte. Estas historias llevan a quien las escucha a reflexionar si constituye un crimen querer unirse a tu esposo o esposa que está trabajando lejos o si es un delito querer ahorrar dinero para construir una casa para los padres ancianos o para los hijos pequeños. Estos relatos presentan a los migrantes como individuos que se arriesgan con el fin de completar deseos y sueños. Se trata de historias con las cuales la mayoría puede identificarse, más allá de su lugar de origen o su situación socioeconómica; ellas invitan a la empatía más que a la simpatía. 
Figura $\mathrm{N}^{\circ} 3$

Omnibus "Altar-Sasabe", realizada con objetos abandonados

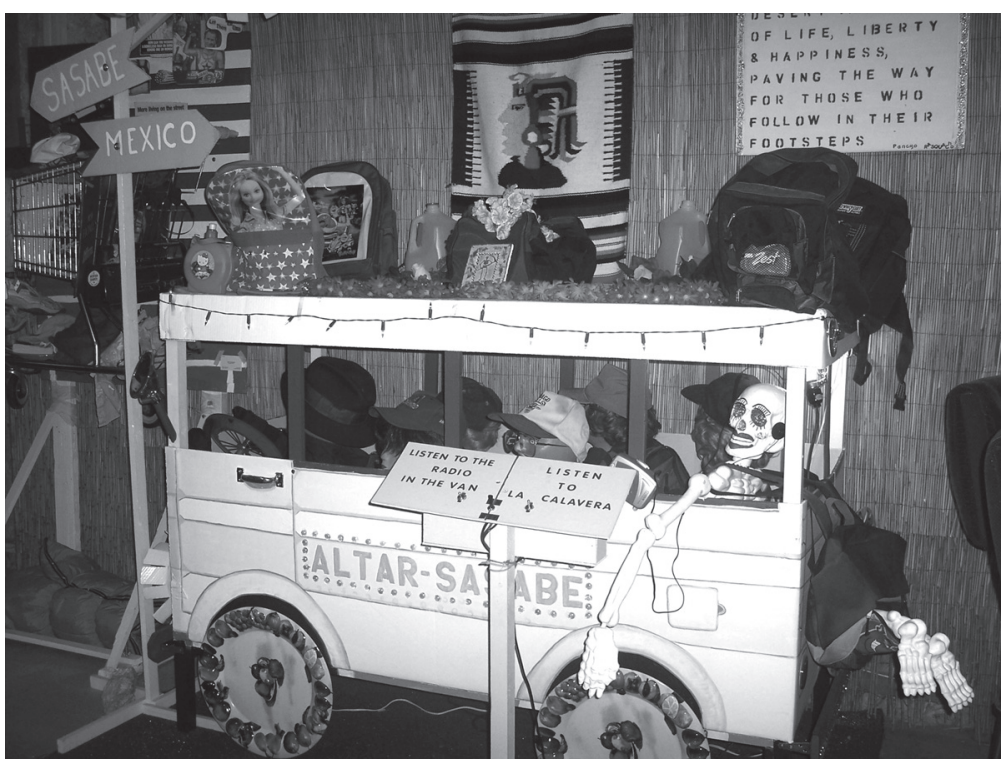

Fuente: Archivo fotográfico personal de la autora.

En síntesis, la instalación de Pancho presenta a los objetos abandonados como pertenencias personales, por lo tanto destacan y desnaturalizan las representaciones que los muestran como residuos. Su emplazamiento contribuye a presentar a los objetos como elementos útiles en la vida cotidiana y necesarios para la vida humana. Más aún, la instalación no diferencia a los migrantes indocumentados de los "estadounidenses" que necesitan cosas para viajar. Al presentar los objetos como pertenencias personales, la instalación opera para romper las fronteras culturales y geopolíticas generadas por las representaciones que actúan en el contexto de la basura.

\section{La política de los relatos sobre "la basura"}

Stoler (2002: 17) sostiene que "las políticas de exclusión", son "contingentes en la selección de criterios culturales" usadas para distinguir entre el "nosotros" y "ellos". En la frontera de Estados Unidos-México, sugiero que un considerable trabajo de carácter cultural y político en los dominios de la intimidad contribuye a asegurar las fronteras geopolíticas. El criterio cultural que alimenta los sistemas cotidianos de distinciones geopolíticas toma en cuenta las nociones naturalizadas del comportamiento del cuerpo y de la higiene. Las expresiones narrativas y las prácticas espaciales establecen el lugar de pertenencia de los objetos íntimos de la vida diaria y el modo en que el cuerpo se relaciona con ellos y opera para establecer un orden social: una conducta apropiada en relación a esos objetos ha definido pertenencia, mientras que el comportamiento considerado inapropiado ordena de forma abrumadora los discursos y prácticas de exclusion. De esta manera, los discursos y prácticas sobre los residuos elaborados por una amplia gama de gru- 
pos constituyen momentos de configuración de la frontera. Estas fronteras son, a la vez, íntimas y geopolíticas.

La demarcación de las categorías geopolíticas a través de las percepciones del sentido común del comportamiento del cuerpo es alarmante, ya que los cuerpos de los migrantes son considerados antihigiénicos y se asocian con la basura. Las movilizaciones políticas construidas sobre estas verdades han alcanzado tal posición dominante en la frontera entre Estados Unidos y México que grupos contrahegemónicos como Fronteras Compasivas son forzados a responder a estas evocaciones. Aún más, el grupo acaba tratando de mitigar las implicaciones políticas de "las conversaciones sobre la basura" y, finalmente, permanencen dentro de su órbita. El trabajo de artistas como Maeve Hicke y Pancho también responden a tales prácticas hegemónicas de catalogación, $y$, en el caso de Pancho, las dejan al descubierto a los fines de incrementar su cuestionamiento.

Finalmente, deseo destacar aquello que queda fuera de la vista, cuando la atención del público se dirige hacia las transgresiones corporales de los migrantes. ¿Qué realidades son enmascaradas por el status no ideológico que se le atribuyen a las normas del sentido común asociadas al comportamiento corporal y al imperativo colectivo de la limpieza? Quizás, el primer elemento que podría desaparecer de los relatos sobre el carácter transgresivo de los desperdicios es el papel que juega el gobierno norteamericano en la creación de esta situación. ¿Después de todo, por qué los migrantes indocumentados que desean trabajar en Estados Unidos son forzados a caminar a través de áreas remotas llevando sus pertenencias? Como mencioné al inicio, la políticas migratorias estadounidenses y de reforzamiento de la frontera han provocado esta situación contradictoria. Además, con la elección de Donald Trump como presidente, no hay cambios a la vista de la legislación migratoria en el Congreso.

En segundo lugar, las "conversaciones sobre los residuos" arrojan luz sobre las heridas sufridas por los "estadounidenses" que consideran que sus espacios nacionales e íntimos son invadidos y destruidos. En consecuencia, las heridas sufridas por los migrantes, ahora expuestos a riesgos ambientales como las asperezas del terreno o las temperaturas extremas son ensombrecidas. Aún más, mi análisis revela que los medios de comunicación y los textos gubernamentales ligados a la acumulación de objetos en el paisaje, rara vez mecionan el terrible riesgo que asumen los migrantes indocumentados y el creciente número de migrantes que mueren por la exposiciónambiental. Mejor dicho, las transgresiones de los migrantes y sus muertes son presentadas de forma separada. Finalmente, me pregunto si la continua asociación entre los migrantes indocumentados y la basura opera de forma de naturalizar y, aún más, justificar las medidas orientadas hacia ellos, en la medida que quienes transgreden las fronteras sociales y políticas, los migrantes indocumentados, "no pertenecen a Estados Unidos".

Sin embargo, si las prácticas sociales mundanas están tan integradas a la producción y sostenimiento de las distinciones geopolíticas cotidianas, ellas también hacen de lo íntimo un dominio significativo de la resistencia. Los encuentros íntimos con los objetos abandonados pueden inspirar indignación, pero tal como lo constataron tanto el personal de Fronteras Compasivasy como el trabajo de Pancho, ellos también pueden provocar identificaciones que trascienden las fronteras políticas. La elaboracion de tales identificaciones es la tarea llevada adelante por los grupos humanitarios, y los objetos abandonados sirven como sitios ideales para permitir encuentros que son tanto íntimos como geopolíticos. 


\section{Referencias bibliográficas}

ANDREAS, P. Border games: policing the U.S.-Mexico divide. Ithaca, NY: Cornell University Press, 2000.

BENDER, S. Greasers and gringos: Latinos, law, and the American imagination. Nueva York: New York University Press, 2003.

BERG, E. \& VAN HOUTUM, H. Routing borders between territories, discourses, and practices. Burlington, VT: Ashgate, 2003.

Claiming Responsibility for Trashing Rep. Kolbe's Office with Border Intruder Garbage. 2003. Disponible en Internet: http://www.petitiononline.com/heykolbe/petition.html

CLANCY-SMITH, J.A. \& GOUDA, F. Domesticating the empire: race, gender, and family life in French and Dutch colonialism. Charlottesville: University Press of Virginia, 1998.

CORNELIUS, W. Controlling "unwanted" immigration: Lessons from the United States, 19932004. Journal of Ethnic and Migration Studies, 2005, Vol. 31, № 4, p. 775-794.

CORNELIUS, W. Death at the border: Efficacy and unintended consequences of US immigration control policy. Population and Development Review, 2001, Vol. 27, № 4, p. 661-685.

CRESSWELL, T. In place/out of place: geography, ideology, and transgression. Minneapolis: University of Minnesota Press, 1996.

CUNNINGHAM, H. God and Caesar at the Rio Grande: sanctuary and the politics of religion. Minneapolis: University of Minnesota Press, 1995.

DAVIS, T. Crossers burying border in garbage. Arizona Daily Star, 30 de Julio de 2006.

DE LEÓN, A. They Called Them Greasers: Anglo Attitudes toward Mexicans in Texas, 1821-1900. Austin: University of Texas Press, 1983.

DE LEÓN, J. Better to be hot than caught: Excavating the conflicting roles of migrant material culture. American Anthropologist, 2012, Vol. 114, N³, p. 477-495.

DITTMER, J. \& GRAY, N. Popular geopolitics 2.0: towards new methodologies of the everyday. Geography Compass, 2010, № 4, p. 1.644-1.677.

DOUGLAS, M. Purity \& Danger: An Analysis of the Concepts of Pollution \& Taboo. Florence: Routledge, 1984.

DOWLER, L. \& SHARP, J. A Feminist Geopolitics? Space \& Polity, 2001, Vol. 5; № 3, p. 165-176.

ENLOE, C. Bananas, beaches \& bases: making feminist sense of international politics. Londres: Pandora, 1989. 
ENLOE, C. Does khaki become you?: the militarisation of women's lives. Londres: Pluto Press, 1983.

FALL, J. Embodied geographies, naturalised boundaries, and uncritical geopolitics en La Frontiere Invisible, Environment and Planning D: Society and Space, 2006, N²4, p. 653-669.

FRONTERA NORTESUR. House Bill Slammed in Mexico. New Mexico: New Mexico State University, Las Cruces: New Mexico Center for Latin American and Border Studies, 2005.

HESS, B. Kolbe's o ice 'trashed': Protesters leave pungent reminder of immigration issue for congressman. 2003. Disponible en Internet: http://www.svherald.com/ articles/2003/09/29/news/ news1.txt.

HILL, S. Purity and Danger on the U.S.-Mexico Border, 1991-1994. South Atlantic Quarterly, 2006, Vol. 105, N 4, p. 777-799.

HUMANE BORDERS (FRONTERAS COMPASIVAS). Home Page. 2005. Disponible en Internet: http:// www.humaneborders.org/index.html

HUMANE BORDERS (FRONTERAS COMPASIVAS). Migrant Encounter Protocols. 2006. Disponible en Internet: http://www.humaneborders.org/volunteer/volunteer_eprotocols.html

HYNDMAN, J. Mind the gap: bridging feminist and political geography through geopolitics. Political Geography, 2004, №23, p. 307-322.

HYNDMAN, J. Beyond Either/or: a feminist analysis of September $11^{\text {th }}$. ACME: An International e-Journal of Critical Geographies, 2003, Vol. 2, № 1, p. 1-13.

HYNDMAN, J. Towards a Feminist Geopolitics. The Canadian Geographer, 2001, Vol. 45, № 2, p. 210-222.

KRAUT, A. Silent Travelers. Germs, genes, and 'immigrant menace. Baltimore: John Hopkins University Press, 1994.

KUUS, M. Intellectuals and geopolitics: The 'cultural politicians' of Central Europe. Geoforum, 2007,38 , p. 241-251.

LATIN AMERICA WORKING GROUP. US Border Patrol Apprehension Statistics 1993-2004. Disponible en Internet: http://www.lawg.org/docs/apprehension\%20stats.pdf

MAGUBANE, Z. Bringing the empire home: race, class, and gender in Britain and colonial South Africa. Chicago: University of Chicago Press, 2004.

MAYER, T. Embodied Nationalisms. In: STAEHELI, L.; KOFMAN, E. \& PEAKE, L. (editors). Mapping women, making politics: feminist perspectives on political geography. Nueva York: Routledge, 2004, p. 153-167. 
MCCLINTOCK, A. Imperial leather: race, gender, and sexuality in the colonial conquest. Nueva York: Routledge, 1995.

MEEHAN, K.; SHAW, I. \& MARSTON, S. Political geographies of the object. Political Geography, 2013, Vol. 33, p. 1-10.

MENCHACA, M. Recovering History, Constructing Race: the Indian, Black, and White Roots of Mexican Americans. Austin: University of Texas Press, 2001.

MOUNTZ, A. \& HYNDMAN, J. Feminist Approaches to the Global Intimate. Women's Studies Quarterly, 2006, Vol. 34, No 1-2, p. 446-463.

MOUNTZ, A. Embodying the nation-state: Canada's response to human smuggling. Political Geography, 2004, Vol. 23, N³, p. 323-345.

NEVINS, J. Operation Gatekeeper: the rise of the "illegal alien" and the remaking of the U.S.-Mexico boundary Nueva York: Routledge, 2002.

NEWMAN, D. Boundaries, Territory and Postmodernity. Londres: Frank Cass Publishers, 1999.

PAASI, A. Territories, boundaries, and consciousness: the changing geographies of the Finnish-Russian boundary. Nueva York: J. Wiley \& Sons, 1996.

PAASI, A. Boundaries as Social Processes: Territoriality in the World of Flows. In: NEWMAN, D. (editor). Boundaries, Territory and Postmodernity. Londres: Frank Cass Publishers, 1999, p. 69 - 88.

PRATT, G. \& ROSNER, V. Introduction: The Global \& the Intimate. In: PRATT, G. \& ROSNER, V. (editors). Women's Studies Quarterly, 2006, Vol. 34, № 1-2, p. 13-24.

RAENTO, P. Communicating geopolitics through postage stamps: the case of Finland. Geopolitics, 2006, 11, p. 601-629.

RANSOM, D. The other America - Tucson or Not Tucson. New Internationalist, 2002, p. 351. Disponible en Internet: http://www.newint.org/features/2002/11/01/introduction

RICO, G. Border Patrol claims 80\% rate of capture. Tucson Citizen, 3 de julio de 2004.

ROMO, D. Ringside seat to a revolution: an underground cultural history of El Paso and Juarez, 1893-1923. El Paso: Cinco Puntos Press, 2005.

ROTHSTEIN, A. Dumping, illegal immigrants go hand-in-hand. Arizona Daily Sun, 12 de julio de 2004.

RUBIO-GOLDSMITH, R.; MCCORMICK, M.; MARTINEZ, D. \& DUARTE, I. The "funnel effect" and recovered bodies of unauthorized migrants processed by the Pima County Office of the Medical Examiner, 1990-2005. Tucson: Binational Migration Institute, University of Arizona, 2006. 
SHARP, J. Condensing the Cold War: Reader's digest and American identity. Minneapolis: University of Minnesota Press, 2001.

SHARP, J. Hegemony, popular culture and geopolitics: The Reader's Digest and the construction of danger. Political Geography, 1996, N 15, p. 557-570.

SOUTHEAST ARIZONA REPUBLICAN CLUB. Kolbe/Bush Amnesty Proposals Protested at Kolbe Town Hall Meeting. 2004. Disponible en Internet: http://www.searclub.com/?page=news-article\&id=209.

SQUIRE, V. Desert 'trash': Posthumanism, Border Struggles, and Humanitarian Politics. Political Geography, 2014, Vol. 39, p. 11-21.

SQUIRE, V. Reshaping Critical Geopolitics? the Materialist Challenge. Review of International Studies, 2015, Vol. 41, No. 1, p. 139-159.

STAEHELI, L.; KOFMAN, E. \& PEAKE, L. (editors). Mapping women, making politics: feminist perspectives on political geography. Nueva York: Routledge, 2004.

STERN, A. Eugenic Nation: faults and frontiers of better breeding in Modern America. Berkeley: University of California Press, 2005.

STOLER, A.L. Race and the education of desire: Foucault's History of sexuality and the colonial order of things. Durham, NC: Duke University Press, 1985.

STOLER, A.L. Tense and Tender Ties: The politics of comparison in North American History and (post) colonial studies. The Journal of American History, 2001, Vol. 88, № 3, p. 829-865.

STOLER, A.L. Carnal knowledge and imperial power: race and the intimate in colonial rule. Berkeley: University of California Press, 2002.

STOLER, A.L. Haunted by empire: geographies of intimacy in North American history. Durham: Duke University Press, 2006.

SUNDBERG, J. \& KASERMAN, B. Cactus Carvings and Desert Defecations: Embodying Representations of Border Crossings in Protected Areas on the Mexico-US Border. Environment and Planning D: Society \& Space, 2007, N² 25, p. 727-744.

THRIFT, N. It's the Little Things. In: DODDS, K. \& ATKINSON, D. Geopolitical traditions: a century of geopolitical thought. Nueva York: Routledge, 2000, p. 380-387.

TURF, L. Illegals turn desert into trash dump. Tucson Citizen, 29 de julio de 2003.

U.S. CONGRESSIONAL RECORD. Strengthening American Borders Against Illegal Immigration. Washington, D.C.: U.S. Congress, 8 April 20O3, p. H2918 - H2922. 
U.S. Customs \& Border Protection. 2016. Southwest Border Deaths By Fiscal Year. Disponible en Internet: https://www.cbp.gov/sites/default/files/assets/documents/2016-Oct/BP\%20Southwest\%2OBorder\%20Sector\%20Deaths\%2OFY1998\%20-\%2OFY2016.pdf

U.S. DEPARTMENT OF THE INTERIOR; U.S. FOREST SERVICE; U.S. ENVIRONMENTAL PROTECTION AGENCY \& U.S. DEPARTMENT OF JUSTICE. Report to the House of Representatives Committee on Appropriations on Impacts Caused by Illegal Aliens Crossing Federal Lands in Southeast Arizona, 2002.

Disponible en Internet: http://www.blm.gov/az/undoc_aliens/SEAZ_REPORT2.pdf

U.S. GOVERNMENT ACCOUNTABILITY OFFICE. Illegal Immigration. Status of Southwest Border Strategy Implementation, 1999.

Disponible en Internet: http://www.gao.gov/archive/1999/gg99044.pdf

U.S. GOVERNMENT ACCOUNTABILITY OFFICE. Illegal Immigration: Border-Crossing Deaths Have Doubled Since 1995; Border Patrol's Efforts to Prevent Deaths Have Not Been Fully Evaluated, 2006. Disponible en Internet: http://www.gao.gov/htext/d06770.html.

VAN HOOK, J., BEAN, F. \& PASSEL, J. Unauthorized Migrants Living in the United States: A Mid-Decade Portrait. Migration Information Source, September 2005. Disponible en Internet: http://www. migrationinformation.org/Feature/display.cfm?ID=329

VANDERPOOL, T. In desert heat, furor over migration simmers on. Christian Science Monitor, 14 de julio de 2003. Disponible en Internet:

http://www.csmonitor.com/2003/0714/p02s02-ussc.html

WASTL-WALTER, D. \& STAEHELI, L. Territory, Territoriality, and Boundaries. In: STAEHELI, L.; KOFMAN, E. \& PEAKE, L. (editors). Mapping women, making politics: feminist perspectives on political geography. Nueva York: Routledge, 2004, p. 141-151. 